\title{
Crystallization and Chain Conformation of Semicrystalline and Amorphous Polymer Blends Studied by Wide-Angle and Small-Angle Scattering
}

\author{
CHING-I HUANG, JUN-RONG CHEN \\ Materials Science and Technology Program, Graduate Institute of Engineering Technology, National Taiwan University of \\ Science and Technology, Taipei 106, Taiwan
}

Received 16 May 2001; revised 17 July 2001; accepted 21 August 2001

\begin{abstract}
We examine the crystallization and chain conformation behavior of semicrystalline poly(ethylene oxide) (PEO) and amorphous poly(vinyl acetate) (PVAc) mixtures with wide-angle X-ray diffraction (WAXD), small-angle X-ray scattering (SAXS), and small-angle neutron scattering (SANS) experiments. For blends with PEO weight fractions $\left(\mathrm{wt}_{\mathrm{PEO}}\right)$ greater than or equal to 0.3 , below the melting point of $\mathrm{PEO}$, the WAXD patterns reveal that crystalline PEO belongs to the monoclinic system. The unit-cell parameters are independent of $\mathrm{wt}_{\mathrm{PEO}}$. However, the bulk crystallinity determined from WAXD decreases as $\mathrm{wt}_{\mathrm{PEO}}$ decreases. The scattered intensities from SAXS experiments show that the systems form an ordered crystalline/amorphous lamellar structure. In a combination of WAXD and SAXS analysis, the related morphological parameters are assigned correctly. With the addition of amorphous PVAc, both the average amorphous layer thickness and long spacing increase, whereas the average crystalline layer thickness decreases. We find that a two-phase analysis of the correlation function from SAXS, in which the scattering invariant is linearly proportional to the volume fraction of lamellar stacks, describes quantitatively the crystallization behavior of PEO in the presence of PVAc. When $\mathrm{wt}_{\mathrm{PEO}}$ is close to 1 , the samples are fully spaced-filled with lamellar stacks. As wt $\mathrm{PEO}_{\mathrm{PEO}}$ decreases from 1.0 to 0.3 , more PVAc chains are excluded from the interlamellar region into the interfibrillar region. The fraction outside the lamellar stacks, which is completely occupied with PVAc chains, increases from 0 to 58\%. Because the radius of gyration of PVAc with a random-coil configuration determined from SANS is smaller than the average amorphous layer thickness from SAXS, we believe that the amorphous PVAc chains still persist with a random-coil configuration even when the blends form an ordered structure. (C) 2001 John Wiley \& Sons, Inc. J Polym Sci Part B: Polym Phys 39: 2705-2715, 2001
\end{abstract}

Keywords: crystallization; chain conformation; wide-angle X-ray diffraction (WAXD); SAXS; small-angle neutron scattering (SANS); blends

\section{INTRODUCTION}

The phase behavior of crystalline polymer blends has attracted a lot of attention over the years.

Correspondence to: C.-I. Huang (E-mail: chingi@mail. ntust.edu.tw)

Journal of Polymer Science: Part B: Polymer Physics, Vol. 39, 2705-2715 (2001) (c) 2001 John Wiley \& Sons, Inc.
Much of the research has focused on crystalline/ amorphous binary polymer blends. ${ }^{1-16}$ For blends with at least one crystallizable component, most studies have been concerned with the morphology associated with the crystallization behavior. Much of the interest lies in the location of the amorphous polymer in the microstructure and the factors that influence the morphology development, such as the mobility and immiscibility be- 
tween the crystalline and amorphous components. ${ }^{11}$ However, the chain conformation of each component, which plays a very important role in determining the location of each component and the morphological patterns, has not been fully understood. ${ }^{3,16}$ In this article, we study both the chain conformation and crystallization behavior of semicrystalline and amorphous polymer mixtures. In particular, the effects of the addition of an amorphous polymer and temperature are examined.

We consider a model system of semicrystalline poly(ethylene oxide) (PEO) and amorphous poly(vinyl acetate) (PVAc). The melting point of PEO is around $60{ }^{\circ} \mathrm{C}$. It is well known that PEO and PVAc are miscible over a wide range of temperatures and polymer compositions., ${ }^{1,4-6,8-12} \mathrm{Al}-$ though there have been some studies concerned with the microstructure of PEO/PVAc blends associated with the crystallization of $\mathrm{PEO}$, most of them were examined with small-angle X-ray scattering (SAXS) experiments. ${ }^{11}$ However, the controversy over the SAXS analysis with the correlation function ${ }^{17}$ and the interphase distribution function ${ }^{18-20}$ lies in the determination of the correct morphological parameters (crystalline layer thickness and amorphous layer thickness). Therefore, we employ both wide-angle X-ray diffraction (WAXD) and SAXS methods to probe the crystallization behavior of PEO in the presence of PVAc. This combination of WAXD and SAXS has been shown to be more appropriate in the analysis of morphological patterns that associate with the crystallization process. ${ }^{21}$

From the WAXD analysis, both the crystal structure and bulk crystallinity $\left(\omega_{\mathrm{mc}}\right)$ are determined. From the one-dimensional (1D) correlation function via the SAXS analysis, two thickness parameters $\left(L_{1}\right.$ and $\left.L_{2}\right)$ are obtained. In a comparison of $\omega_{\mathrm{mc}}, L_{1} /\left(L_{1}+L_{2}\right)$, and $L_{2} /\left(L_{1}+L_{2}\right)$, the average crystalline layer thickness and the average amorphous layer thickness can be assigned correctly. In addition, we compare the scattering invariant determined by both experiment and calculation, from which the fraction of lamellar stacks in the material and the location of both PEO and PVAc components can be determined quantitatively. Thus far, there have been no studies that analyze the morphological patterns of PEO/PVAc blends with a combination of WAXD and SAXS. We also employ small-angle neutron scattering (SANS) experiments to study the chain conformation of PEO/PVAc mixtures. In particular, we determine the net interaction pa- rameter $(\chi)$, which is characteristic of the incompatibility between PEO and PVAc, and the radii of gyration of PEO and PVAc as a function of temperature and composition.

\section{EXPERIMENTAL}

\section{Materials and Sample Preparation}

The samples used in this study were mixtures of PEO and PVAc. PVAc with a molecular weight of 113,000 was purchased from Aldrich Chemical Co. PEO was purchased from Acros Organics Co. and had a molecular weight of 100,000 . The mixtures were prepared by solution casting from chloroform at room temperature. The resulting films were evaporated in air at room temperature for 2 days and then under vacuum at $90^{\circ} \mathrm{C}$ for $6 \mathrm{~h}$ to ensure complete solvent removal. The cast films were cut and compressed into $\mathrm{Cu}$-window sample cells. The specimens were then kept at 90 ${ }^{\circ} \mathrm{C}$ in the oven to remove bubbles and voids. The samples were rapidly transferred to another oven preheated to $50{ }^{\circ} \mathrm{C}$ and were allowed to crystallize for $24 \mathrm{~h}$.

\section{WAXD}

WAXD experiments were carried out on the blend samples with a Rigaku Denki diffractometer with $\mathrm{Cu} \mathrm{K} \alpha$ radiation $(\lambda=1.542 \AA)$ at a scanning rate of $1^{\circ} \theta / \mathrm{min}$, where $\theta$ is the scattering angle (the angle between the incident X-ray beam and the scattered X-ray beam). The accelerating voltage was $40 \mathrm{kV}$, and the tube current was $100 \mathrm{~mA}$. The $\mathrm{X}$ rays were monochromated with a graphite. All measurements were performed at room temperature.

\section{SAXS}

SAXS experiments were carried out at National Tsing Hua University (Hsin-Chu, Taiwan). $\mathrm{Cu} \mathrm{K} \alpha$ $\mathrm{X}$ rays $(\lambda=1.542 \AA)$ were generated from an $18 \mathrm{Kw}$ Rigaku rotating anode. The power source was operated at $200 \mathrm{~mA}$ and $40 \mathrm{kV}$. The $\mathrm{X}$ rays were monochromated with graphite. Collimation of the X-ray beam was achieved with a set of three pinholes. The sizes of the first and second pinholes were 1.5 and $1.0 \mathrm{~mm}$, respectively, and the size of the guard pinhole before the sample was $2.0 \mathrm{~mm}$. The scattered intensity was collected by a two-dimensional position-sensitive detector (20 


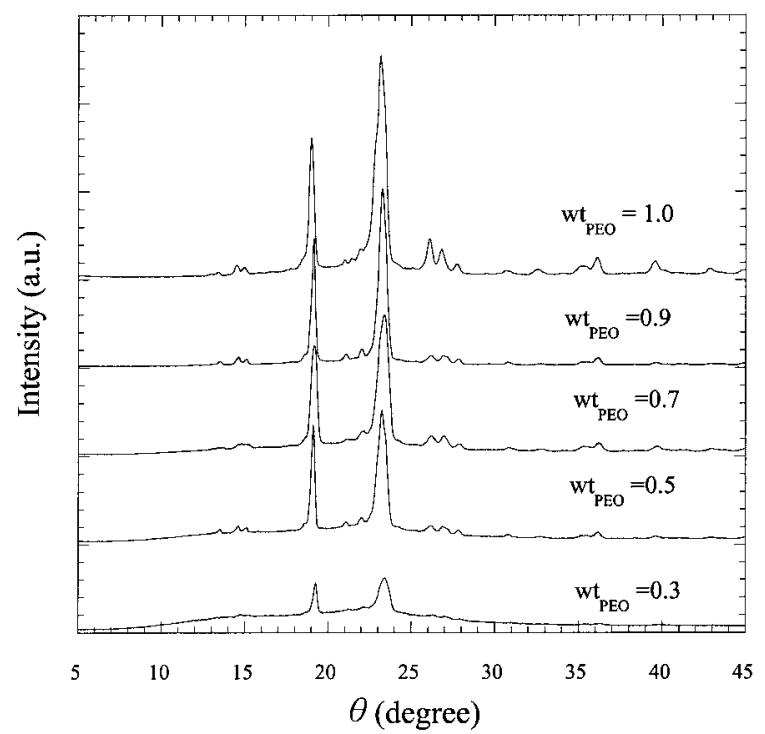

Figure 1. WAXD patterns in terms of the intensity and $\theta$ for the PEO/PVAc blends with various values of $\mathrm{wt}_{\mathrm{PEO}}$ crystallized at $50{ }^{\circ} \mathrm{C}$ for $24 \mathrm{~h}$.

$\times 20 \mathrm{~cm}^{2}$ ) with approximately 1 -mm resolution. The sample-to-detector distance was $2.27 \mathrm{~m}$. The beam stop was a round lead disk $18 \mathrm{~mm}$ in diameter. The data were corrected for background and detector response and then azimuthally averaged to the $1 \mathrm{D}$ form of the intensity $(I)$ versus the scattering wavevector $[q=(4 \pi / \lambda) \sin (\theta / 2)]$. All measurements were performed at room temperature.

\section{SANS}

SANS experiments were performed at the Cold Neutron Research Facility of the National Institute of Standards and Technology (United States) with the SANS $8 \mathrm{~m}$ instrument. A wavelength $\lambda$ of $9 \AA$ A was used. The sample-to-detector distance was $3.6 \mathrm{~m}$. First, the blends were crystallized at $50{ }^{\circ} \mathrm{C}$ for $24 \mathrm{~h}$ and measured at room temperature. The samples were then heated and equilibrated at the desired temperature at least $20 \mathrm{~min}$ before measurement. In addition to the blend samples, SANS measurements were carried out on the pure homopolymers to estimate the incoherent background.

The scattering data were corrected for detector sensitivity, transmission, background, sample thickness, and empty cell contributions. The data were placed on an absolute scale with a calibrated silica standard (A3) and then azimuthally averaged. An incoherent scattered intensity from the homopolymer contributions was subtracted from the data. A small positive scattering intensity due to other uncertainties was removed. This magnitude was very small and typically about $0.1 \mathrm{~cm}^{-1}$, which was within the experimental error.

\section{RESULTS AND DISCUSSION}

\section{Crystallization Behavior}

\section{WAXD Analysis}

The WAXD patterns in terms of $I$ and $\theta$ for $\mathrm{PEO} /$ PVAc blends with various values of the PEO weight fraction $\left(\mathrm{wt}_{\mathrm{PEO}}\right)$ crystallized at $50{ }^{\circ} \mathrm{C}$ for $24 \mathrm{~h}$ are shown in Figure 1. It is clear that the peak positions from the WAXD profiles are almost identical, which indicates that the crystallizable PEO chains form a similar unit-cell structure for the blends studied here. The peak positions from our blend samples in Figure 1 are consistent with those from ref. 22, indicating that $\mathrm{PEO}$ belongs to the monoclinic crystal system. ${ }^{23}$ To analyze the unit-cell structure parameters, we have indexed the main peaks as suggested in ref. 22. For example, in Figure 2(a), five of the main peaks are indexed for the WAXD pattern from a pure PEO sample. For a monoclinic system, the interplanar spacing of the $(h k l)$ reflection planes is given by

$$
\begin{aligned}
\left(\frac{1}{d_{h k l}}\right)^{2} & =\left(\frac{2 \sin \left(\theta_{h k l} / 2\right)}{\lambda}\right)^{2} \\
& =\frac{1}{\sin ^{2} \beta}\left(\frac{h^{2}}{a^{2}}+\frac{k^{2} \sin ^{2} \beta}{b^{2}}+\frac{l^{2}}{c^{2}}-\frac{2 h l \cos \beta}{a c}\right)
\end{aligned}
$$

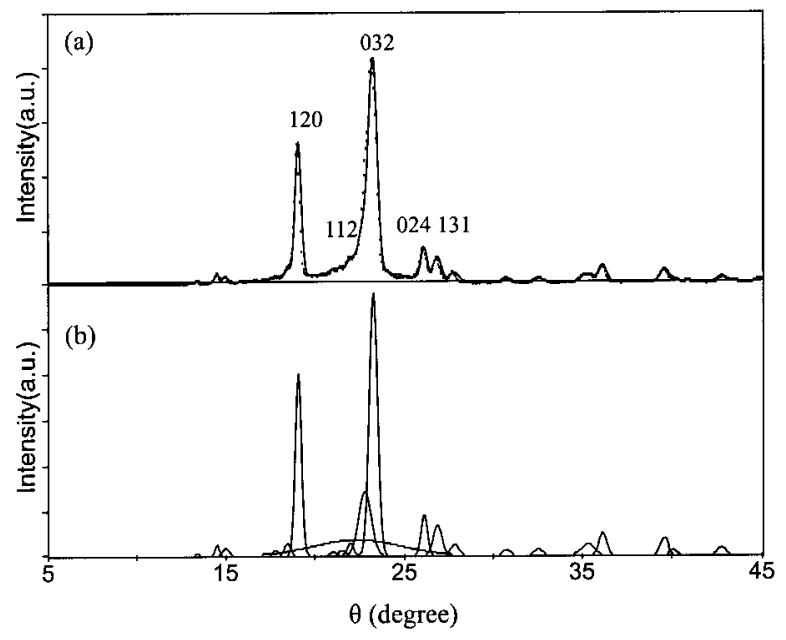

Figure 2. (a) WAXD pattern and (b) peak deconvolution of the WAXD profile for a pure PEO sample. 
Table I. Unit-Cell Structure Parameters of PEO Crystals in the Presence of PVAc as Determined from WAXD Measurements

\begin{tabular}{cccc}
\hline $\mathrm{wt}_{\text {PEO }}$ & $a(\AA)$ & $b(\AA)$ & $c(\AA)$ \\
\hline 1.0 & 8.13 & 13.13 & 19.58 \\
0.9 & 8.11 & 13.05 & 19.64 \\
0.7 & 8.10 & 13.00 & 19.56 \\
0.5 & 8.11 & 13.05 & 19.64 \\
0.3 & 8.02 & 13.00 & 19.41 \\
\hline
\end{tabular}

Through the insertion of the values of $\lambda(1.542 \AA)$, $\beta\left(125.4^{\circ}\right.$, as in ref. 22$)$, and the peak positions of (120), (032), and (024) reflection planes, the unitcell parameters $a, b$, and $c$ are determined by eq 1 and listed as a function of $\mathrm{wt}_{\mathrm{PEO}}$ in Table I. As shown in Table I, the unit-cell parameters are independent of $\mathrm{wt}_{\mathrm{PEO}}$. That is, the crystal unitcell structure of PEO remains the same with the addition of amorphous PVAc. However, the PVAc amount added to $\mathrm{PEO}$ has a great influence on the crystallinity of blend samples.

$\omega_{\mathrm{mc}}$ for PEO, as determined from WAXD, is calculated by the division of the sum of the crystalline reflection intensities by the total intensity. By deconvoluting the WAXD profiles to a combination of possible crystalline reflections as well as the amorphous phase with Gaussian curves, we separate the intensities contributed from each crystalline reflection plane as well as the amorphous phase. For example, the WAXD deconvolution results from pure PEO samples are presented in Figure 2(b). All of the reflection planes as well as the corresponding $\theta$ values used in the deconvolution procedure for pure PEO are listed in Table II. The $\theta$ values with respect to $(h k l)$

Table II. Reflection Planes and Corresponding $\theta$ Values Used in the Deconvolution Procedure for PEO

\begin{tabular}{rrrrrrrr}
\hline$h$ & $k$ & $l$ & $\theta\left(^{\circ}\right)$ & $h$ & $k$ & $l$ & $\theta\left(^{\circ}\right)$ \\
\hline 1 & 0 & 0 & 13.4 & 0 & 3 & 2 & 23.2 \\
0 & 2 & 1 & 14.6 & 0 & 2 & 4 & 26.1 \\
1 & 1 & 0 & 15.0 & 1 & 3 & 1 & 26.7 \\
0 & 1 & 3 & 18.0 & 1 & 1 & 3 & 27.8 \\
1 & 1 & 1 & 18.5 & 2 & 0 & 1 & 30.6 \\
1 & 2 & 0 & 19.0 & 1 & 1 & 4 & 32.9 \\
0 & 3 & 1 & 21.0 & 1 & 4 & 2 & 35.1 \\
0 & 2 & 3 & 21.5 & 1 & 2 & -7 & 36.1 \\
1 & 2 & 1 & 21.9 & 2 & 0 & 3 & 39.5 \\
1 & 1 & 2 & 22.9 & -1 & 4 & -4 & 42.6 \\
\hline
\end{tabular}

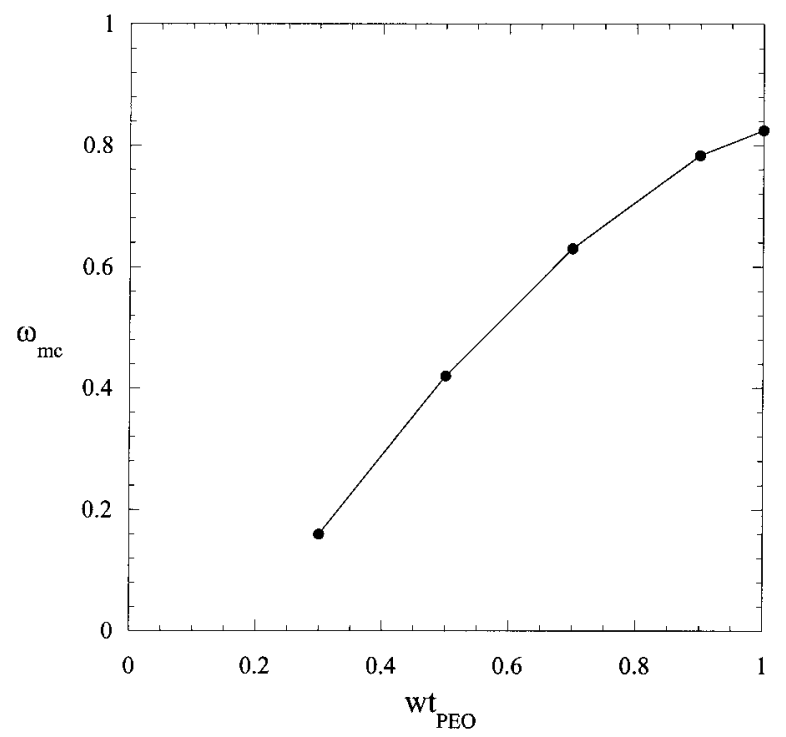

Figure 3. $\omega_{\mathrm{mc}}$ determined from WAXD measurements as a function of $\mathrm{wt}_{\mathrm{PEO}}$.

planes are calculated by the insertion of the unitcell parameters into eq 1 . Similar procedures are employed for the blend samples examined here. In Figure 3, we plot $\omega_{\mathrm{mc}}$ versus wt $\mathrm{PEO}_{\mathrm{PEO}}$ As expected, when $\mathrm{wt}_{\mathrm{PEO}}$ decreases, $\omega_{\mathrm{mc}}$ decreases.

\section{SAXS Analysis}

The SAXS intensity profiles are corrected by the subtraction of the background intensity arising from the thermal density fluctuation $\left(I_{\mathrm{b}}\right)$ with the aid of Porod-Ruland model: ${ }^{24}$

$$
I(q)=K \frac{\exp \left(-\sigma^{2} q^{2}\right)}{q^{4}}+I_{\mathrm{b}}
$$

where $K$ is the Porod constant and $\sigma$ is related to the thickness of crystalline/amorphous interphases. The values of $K, \sigma$, and $I_{\mathrm{b}}$ are obtained by the curve fitting of the intensity at a high $q$ range $\left(0.10-0.15 \AA^{-1}\right)$. A series of Lorentz-corrected scattering profiles $\left[\left(I-I_{\mathrm{b}}\right) q^{2}\right.$ vs $\left.q\right]$ obtained from SAXS experiments for PEO/PVAc blends crystallized at $50{ }^{\circ} \mathrm{C}$ for $24 \mathrm{~h}$ are shown in Figure 4 . As can be seen, the peak position $\left(q^{*}\right)$ shifts toward smaller scattering wavevectors with a decreasing amount of PEO. That is, the long spacing calculated from Bragg's law $\left(L_{\mathrm{B}}=2 \pi / q^{*}\right)$, as listed in Table III, increases with the addition of amorphous PVAc.

To obtain the average crystalline layer thickness $\left(L_{\mathrm{C}}\right)$ and average amorphous layer thickness 


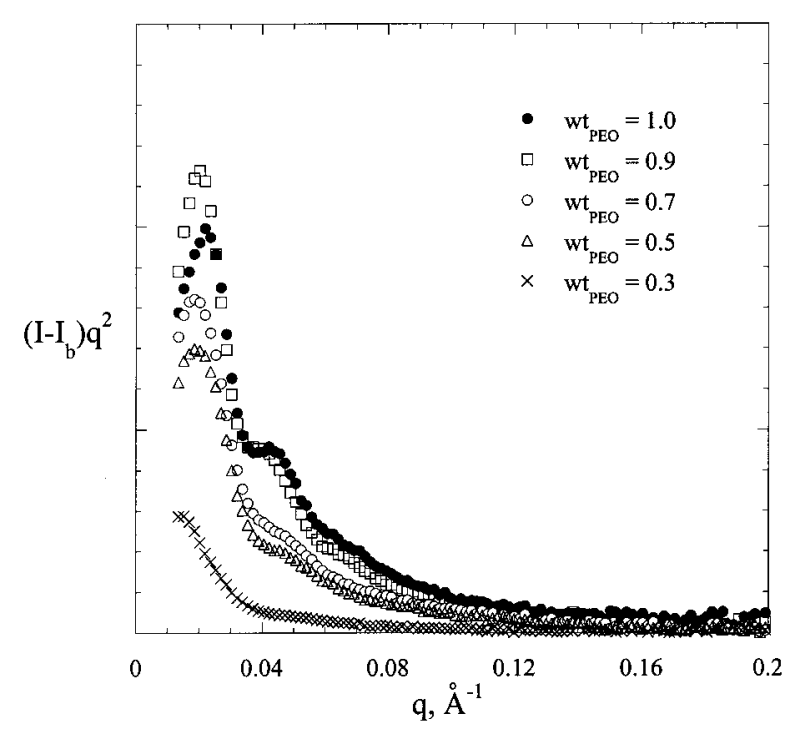

Figure 4. Profiles of the Lorentz-corrected intensity from SAXS measurements for PEO/PVAc blends crystallized at $50{ }^{\circ} \mathrm{C}\left(\mathrm{wt}_{\mathrm{PEO}}\right.$ is indicated in the figure).

$\left(L_{\mathrm{A}}\right)$, the normalized 1D correlation function $[\gamma(x)]$, defined as $^{17}$

$$
\gamma(x)=\frac{1}{Q} \times\left\{\frac{1}{2 \pi^{2}} \int_{0}^{\infty}\left(I(q)-I_{\mathrm{b}}\right) q^{2} \cos (q x) d q\right\}
$$

needs to be evaluated. In eq 3 , the scattering invariant $(Q)$ is defined as $\frac{1}{2 \pi^{2}} \int_{0}^{\infty}\left[I(q)-I_{\mathrm{b}}\right] q^{2} d q$. As a result, the correlation function becomes 1 at $x=0$. Because the experimentally accessible $q$ range is finite, the extrapolation of the scattered intensity to both low $q$ and high $q$ is necessary. The extension to high $q$ data is performed as mentioned previously in eq 2. The extrapolation to zero $q$ data is obtained by the curve fitting of the inten-

Table III. Morphological Parameters Determined from Bragg's Law and 1D Correlation Functions for Blends of PEO and PVAc Crystallized at $50{ }^{\circ} \mathrm{C}$ for $24 \mathrm{~h}$

\begin{tabular}{|c|c|c|c|c|c|c|}
\hline$w t_{\text {PEO }}$ & $\begin{array}{l}L_{\mathrm{B}} \\
(\AA)\end{array}$ & $\begin{array}{c}B \\
(\AA)\end{array}$ & $\begin{array}{c}L_{1 \mathrm{D}}^{\mathrm{M}} \\
(\AA)\end{array}$ & $\begin{array}{c}L_{1 \mathrm{D}}^{\mathrm{m}} \\
(\AA)\end{array}$ & $\begin{array}{l}L_{\mathrm{C}} \\
(\AA)\end{array}$ & $\begin{array}{l}L_{\mathrm{A}} \\
(\AA)\end{array}$ \\
\hline 1.0 & 270 & 45 & 278 & 244 & 222 & 56 \\
\hline 0.9 & 300 & 50 & 297 & 260 & 233 & 64 \\
\hline 0.7 & 334 & 58 & 290 & 260 & 210 & 80 \\
\hline 0.5 & 349 & 66 & 290 & 280 & 188 & 102 \\
\hline 0.3 & 449 & 90 & 382 & 326 & 145 & 237 \\
\hline
\end{tabular}

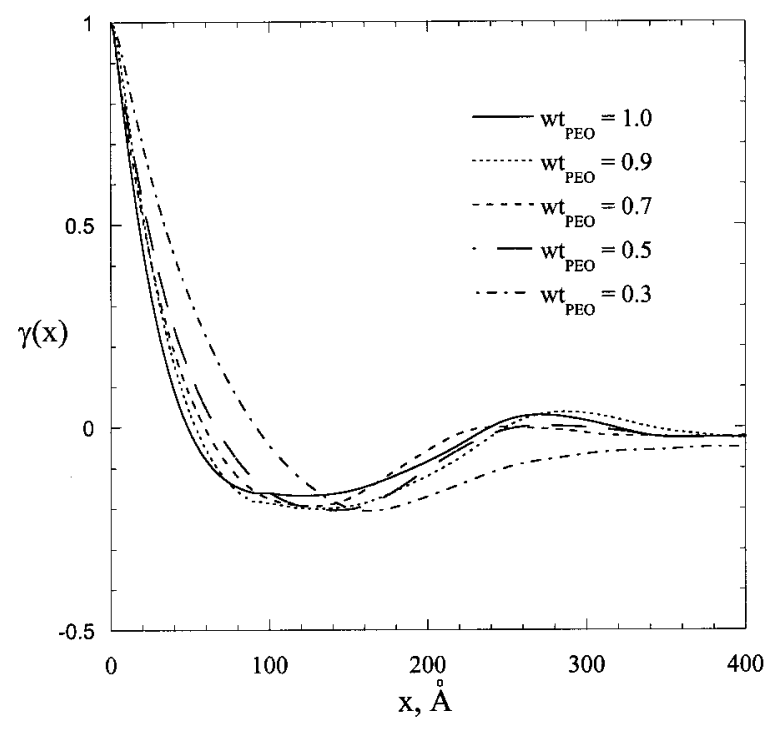

Figure 5. 1D correlation functions deduced from SAXS profiles of PEO/PVAc blends crystallized at $50{ }^{\circ} \mathrm{C}$ ( $\mathrm{wt}_{\mathrm{PEO}}$ is indicated in the figure).

sity at a low $q$ range $\left(0.013-0.03 \AA^{-1}\right)$ with the Debye-Bueche model: ${ }^{25,26}$

$$
I(q)=\frac{I(0)}{\left(1+q^{2} \xi^{2}\right)^{2}}
$$

where $\xi$ is the correlation length. Once the extrapolations to both high $q$ and low $q$ range data are done, $\gamma(x)$ is calculated with eq 3 . The value of the long spacing is, therefore, estimated as (1) the first maximum $\left(L_{1 D}^{M}\right)$ and (2) twice the position of the first minimum $\left(L_{1 D}^{m}\right)$ in the 1D correlation function $\gamma(x)$. The value $L_{1 D}^{M}$ corresponds to the most probable distance between two adjacent crystals, whereas $L_{1 D}^{m} / 2$ represents the most probable distance between a crystal and its adjacent amorphous layer region. In general, $L_{1 D}^{M}$ and $L_{1 D}^{m}$ do not coincide unless the lamellae form an ideal two-phase structure. In addition, the linear crystallinity $\left(X_{\mathrm{CL}}\right)$ is determined by

$$
B=X_{1}\left(1-X_{1}\right) L_{1 D}^{M}
$$

where $B$ is the position of the first intercept of the correlation function $\gamma(x)$ with the $x$ axis. In eq 5 , either $X_{1}$ or $1-X_{1}$ corresponds to $X_{\mathrm{CL}}=L_{\mathrm{C}} / L_{1 D}^{M}$, from which $L_{\mathrm{C}}$ and $L_{\mathrm{A}}=L_{1 D}^{M}-L_{\mathrm{C}}$ can be determined.

In Figure 5, we plot $\gamma(x)$ for $\mathrm{wt}_{\mathrm{PEO}}=1.0,0.9$, $0.7,0.5$, and 0.3 , from which $B, L_{1 D}^{M}$, and $L_{1 D}^{m}$ are determined and listed in Table III. We then ob- 


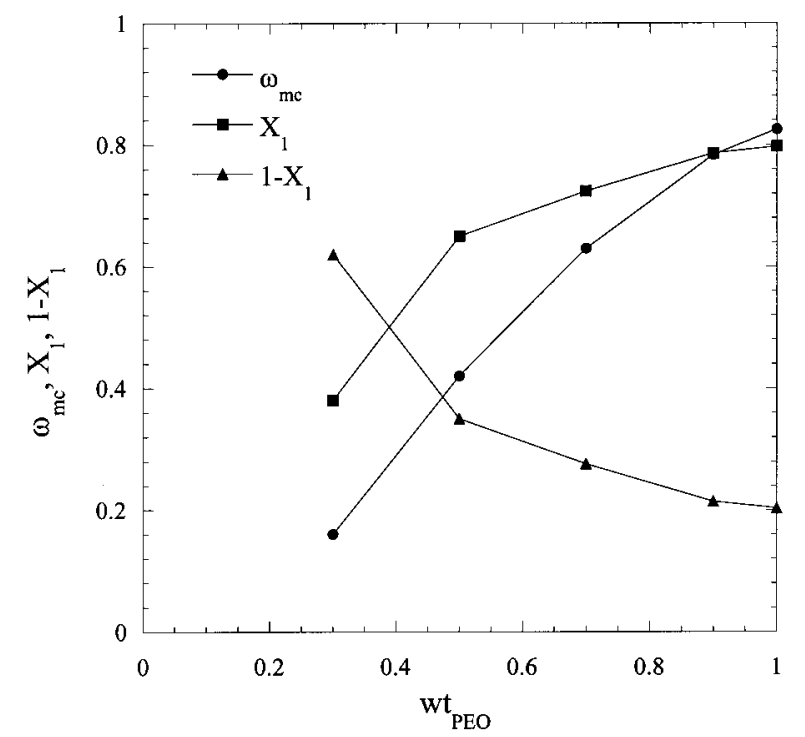

Figure 6. Variations of $X_{\mathrm{CL}}\left(X_{1}\right.$ or $\left.1-X_{1}\right)$ determined from SAXS measurements and $\omega_{\mathrm{mc}}$ determined from WAXD measurements.

tain two solutions, $X_{1}$ and $1-X_{1}$, with eq 5 . To distinguish whether $X_{1}$ or $1-X_{1}$ represents $X_{\mathrm{CL}}$, we present $X_{1}, 1-X_{1}$, and $\omega_{\mathrm{mc}}$ from WAXD as a function of $\mathrm{wt}_{\mathrm{PEO}}$ in Figure 6 . As can be seen, if we assign the lower value $1-X_{1}$ as $X_{\mathrm{CL}}$, it would suggest that the volume fraction of lamellar stacks $\left(X_{\mathrm{L}}=\omega_{\mathrm{mc}} / X_{\mathrm{CL}}\right)$ is greater than $100 \%$ for $\mathrm{wt}_{\mathrm{PEO}} \geq 0.5$, which does not make sense. Therefore, it is reasonable to designate $X_{1}$ as $X_{\mathrm{CL}}$. Note that when $\mathrm{wt}_{\mathrm{PEO}}=1.0$, although $X_{\mathrm{L}}=1.03$, which is still greater than 1.0, the exceeding percentage $3 \%$ is within experimental error. Once $X_{\mathrm{CL}}$ is clearly identified, both $L_{\mathrm{C}}$ and $L_{\mathrm{A}}$ are determined and given in Table III. In Figure 7, we also plot the long spacing $\left(L_{\mathrm{B}}, L_{1 D}^{M}\right.$, and $\left.L_{1 D}^{m}\right), L_{\mathrm{C}}$, and $L_{\mathrm{A}}$ as a function of $\mathrm{wt}_{\mathrm{PEO}}$. As expected, both $L_{\mathrm{B}}$ and $L_{1 D}^{m}$ increase with an increasing amount of amorphous PVAc, whereas $L_{1 D}^{M}$ remains in the range of $278-297 \AA$ as $\mathrm{wt}_{\mathrm{PEO}}$ varies from 1.0 to 0.5 and then increases abruptly to $382 \AA$ as $w_{\text {PEO }}$ decreases to 0.3. As the amount of amorphous PVAc increases, $L_{\mathrm{A}}$ increases; however, $L_{\mathrm{C}}$ decreases slightly. In general, we find that $L_{\mathrm{B}}>L_{1 D}^{M}$ $>L_{1 D}^{m}$, which suggests that there exists a broad distribution of long periods for the blend samples with $\mathrm{wt}_{\mathrm{PEO}} \geq 0.3$ crystallized at $50{ }^{\circ} \mathrm{C} .{ }^{18}$ Furthermore, as Santa-Cruz et al. ${ }^{18}$ proposed, the inequality $L_{1 D}^{M}>L_{1 D}^{m}$ holds when the thicker phase has a broader distribution of sizes than the thinner phase. In a comparison of $L_{\mathrm{C}}$ and $L_{\mathrm{A}}$ in Table III, when $\mathrm{wt}_{\mathrm{PEO}} \geq 0.5$, the thicker phase corre- sponds to the crystalline lamellae, which is, therefore, characterized by a broader distribution of sizes than the amorphous phase. However, when $\mathrm{wt}_{\mathrm{PEO}}$ is down to 0.3 , the thinner phase corresponds to the crystalline lamellae, which has a narrower distribution of sizes than the amorphous phase.

Because $X_{\mathrm{CL}}\left(X_{1}\right.$ in our case) and $\omega_{\mathrm{mc}}$ have been determined from SAXS and WAXD, respectively, the fraction of lamellar stacks occupied in the material $\left(X_{\mathrm{L}}\right)$ is easily calculated by $X_{\mathrm{L}}=\omega_{\mathrm{mc}} / X_{\mathrm{CL}}$ and plotted as a function of $\mathrm{wt}_{\mathrm{PEO}}$ in Figure 8 . We find that when wt $\mathrm{PEO}_{\mathrm{PEO}}$ decreases from 1.0 to $0.3, X_{\mathrm{L}}$ decreases from 100 to $42 \%$. This indicates that as the amount of PVAc added to PEO increases, more PVAc chains are excluded from the interlamellar region into the interfibrillar region. Therefore, $X_{\mathrm{L}}$ decreases as $\mathrm{wt}_{\mathrm{PEO}}$ decreases. These results have been observed qualitatively for A and B blends with the interaction parameter between $\mathrm{A}$ and $\mathrm{B}\left(\chi_{\mathrm{AB}}\right)$ close to $0 .^{3,11}$

To further quantify the fraction of PEO in the crystalline and amorphous phases and the volume fraction of PVAc inside and outside the interlamellar stacks, we give a more detailed analysis by comparing both experimental and calculated values of $Q$, which is often written $\operatorname{as}^{27}$

$$
Q=X_{L} X_{C L}\left(1-X_{C L}\right)\left(\rho_{C}-\rho_{A}\right)^{2}
$$

where $\rho_{\mathrm{C}}$ and $\rho_{\mathrm{A}}$ are the scattering length densities of the crystalline layer and amorphous layer,

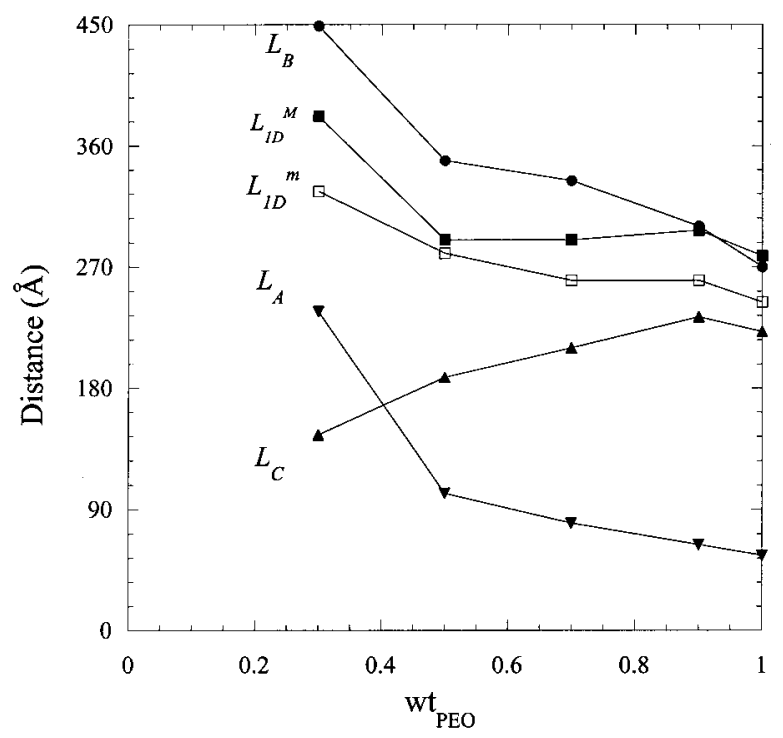

Figure 7. Long spacing deduced from Bragg's law $\left(L_{\mathrm{B}}\right)$ and $1 \mathrm{D}$ correlation functions $\left(L_{1 D}^{M}\right.$ and $\left.L_{1 D}^{m}\right)$ along with $L_{\mathrm{C}}$ and $L_{\mathrm{A}}$ from $1 \mathrm{D}$ correlation functions as a function of $\mathrm{wt}_{\mathrm{PEO}}$. 


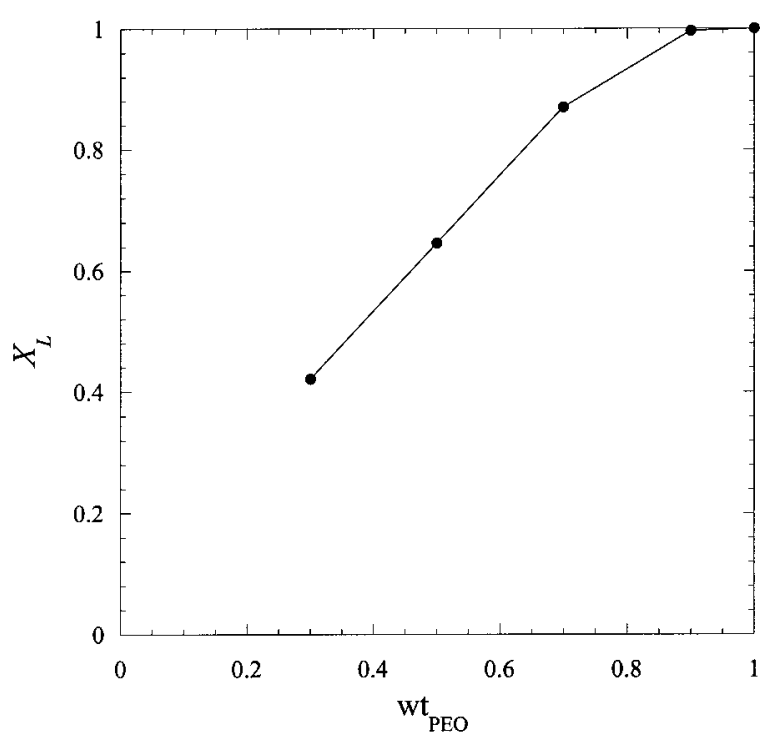

Figure 8. $X_{\mathrm{L}}$ in the bulk as a function of $\mathrm{wt}_{\mathrm{PEO}}$.

respectively. We assume that all of the $\mathrm{PEO}$ chains and partial amounts of the PVAc chains remain in the lamellar stacks. That is, the region outside the lamellar stacks $\left(1-X_{\mathrm{L}}\right)$ is fully occupied with amorphous PVAc. If $\phi_{\mathrm{PVAc}}$ is denoted as the volume fraction of amorphous PVAc, the volume fraction of PVAc remaining outside and inside the lamellar stacks is, therefore, equal to $\phi_{\mathrm{PVAc}, \text { out }}=1-X_{\mathrm{L}}$ and $\phi_{\mathrm{PVAc}, \text { in }}=\phi_{\mathrm{PVAc}}-(1$ $-X_{\mathrm{L}}$ ), respectively. $\rho_{\mathrm{C}}$ and $\rho_{\mathrm{A}}$ are then represented as

$$
\begin{gathered}
\rho_{\mathrm{C}}=\rho_{\mathrm{PEO}, \mathrm{C}}^{\circ} \\
\rho_{\mathrm{A}}=\rho_{\mathrm{PEO}, \mathrm{A}}^{\circ} \times \frac{\phi_{\mathrm{PEO}, \mathrm{A}}}{\phi_{\mathrm{PEO}, \mathrm{A}}+\phi_{\mathrm{PVAc}}-\left(1-X_{\mathrm{L}}\right)}+\rho_{\mathrm{PVAc}}^{\circ} \\
\times \frac{\phi_{\mathrm{PVAc}}-\left(1-X_{\mathrm{L}}\right)}{\phi_{\mathrm{PEO}, \mathrm{A}}+\phi_{\mathrm{PVAc}}-\left(1-X_{\mathrm{L}}\right)}
\end{gathered}
$$

where $\phi_{\mathrm{PEO}, \mathrm{A}}$ represents the volume fraction of amorphous PEO, and $\rho_{P E O, C}^{\circ}, \rho_{P E O, A}^{\circ}$, and $\rho_{P V A c}^{\circ}$, corresponding to the scattering length densities of $100 \%$ crystalline PEO, $100 \%$ amorphous PEO, and PVAc, respectively, are calculated by

$$
\rho_{I}^{\circ}=\frac{b_{I} \times d_{I}^{\circ}}{(m w)_{I}} \times N_{\mathrm{o}}
$$

where $(m w)_{I}$ is the molecular weight of monomer $I, N_{\mathrm{o}}$ is Avogadro's number, and $b_{I}$ is the scattering length per monomer $I$. In eq $8, d_{P E O, C}^{\circ}$,
$d_{P E O, A}^{\circ}$, and $d_{P V A c}^{\circ}$ represent the mass densities of $100 \%$ crystalline PEO, $100 \%$ amorphous PEO, and PVAc and equal 1.24, 1.12, and $1.19 \mathrm{~g} / \mathrm{cm}^{3}$, respectively. ${ }^{28}$ For the X-ray source, $b_{I}$ is equal to the number of electrons per monomer multiplied by $0.282 \times 10^{-12} \mathrm{~cm}$. With the insertion of the related values into eq $8, \rho_{P E O, C}^{\circ}, \rho_{P E O, A}^{\circ}$, and $\rho_{P V A c}^{\circ}$ are equal to $1.148 \times 10^{11}, 1.037 \times 10^{11}$, and 1.081 $\times 10^{11} \mathrm{~cm}^{-2}$, respectively. For eq 7 , the variables $\phi_{\mathrm{PEO}, \mathrm{A}}$ and $\phi_{\mathrm{PVAc}}$ are determined by

$$
\begin{aligned}
& \phi_{\mathrm{PEO}, \mathrm{A}}=\frac{\mathrm{w} \mathrm{t}_{\mathrm{PEO}}\left(1-f_{\mathrm{C}}\right) / d_{\mathrm{PEO}, \mathrm{A}}^{\circ}}{\left(\mathrm{w} t_{\mathrm{PEO}} f_{\mathrm{C}} / d_{\mathrm{PEO}, \mathrm{C}}^{\circ}+\mathrm{w} \mathrm{t}_{\mathrm{PEO}}\left(1-f_{\mathrm{C}}\right) /\right.} \\
& d_{\mathrm{PEO}, \mathrm{A}}^{\circ}+\left(1-\mathrm{wt}_{\mathrm{PEO}}\right) / d_{\mathrm{PVAc}}^{\circ} \\
& \phi_{\mathrm{PVAc}}=\frac{\left(1-\mathrm{wt}_{\mathrm{PEO}}\right) / d_{\mathrm{PVAc}}^{\circ}}{\left(\mathrm{wt}_{\mathrm{PEO}} f_{\mathrm{C}} / d_{\mathrm{PEO}, \mathrm{C}}^{\circ}+\mathrm{wt}_{\mathrm{PEO}}\left(1-f_{\mathrm{C}}\right) /\right.}
\end{aligned}
$$

where $f_{\mathrm{C}}$ is the ratio of crystalline PEO to the overall PEO content and can be determined by $\omega_{\mathrm{mc}}$ from WAXD and the volume fraction of crystalline PEO $\left(\phi_{\mathrm{PEO}, \mathrm{C}}\right)$ being equated:

$$
\begin{aligned}
\omega_{\mathrm{mc}}= & \phi_{\mathrm{PEO}, \mathrm{C}} \\
=\frac{\mathrm{wt}_{\mathrm{PEO}} f_{\mathrm{C}} / d_{\mathrm{PEO}, \mathrm{C}}^{\circ}}{\left(\mathrm{wt}_{\mathrm{PEO}} f_{\mathrm{C}} / d_{\mathrm{PEO}, \mathrm{C}}^{\circ}+\mathrm{wt}_{\mathrm{PEO}}\left(1-f_{\mathrm{C}}\right) / d_{\mathrm{PEO}, \mathrm{A}}^{\circ}\right.} & +\left(1-\mathrm{w} \mathrm{t}_{\mathrm{PEO}}\right) / d_{\mathrm{PVA}}^{\circ}
\end{aligned}
$$

Once $f_{\mathrm{C}}$ is determined with eq $9 \mathrm{c}, Q$ is calculated by eq 6 as mentioned previously. All of the related data are listed in Table IV. To compare $Q$ from both experiment and calculation, we need to rescale the experimental $Q$ because it is in arbitrary units. As shown in Table IV, the ratio of the calculated scattering invariant to the experimental scattering invariant, $Q_{\text {cal }} / Q_{\text {exp }}$, is almost independent of $\mathrm{wt}_{\mathrm{PEO}}$ except for $\mathrm{wt}_{\mathrm{PEO}}=0.3$. We then rescale $Q_{\exp }$ by multiplying the average value $Q_{\text {cal }} / Q_{\text {exp }}$, which is around $20.7 \times 10^{19} \mathrm{~cm}^{-4}$, and compare both $Q_{\text {cal }}$ and scaled $Q_{\exp }$ in Figure 9. It is clear that both experimental and numerical results for $\mathrm{wt}_{\mathrm{PEO}} \geq 0.5$ are within a $5 \%$ experimental error, which suggests that the model adopted here describes quantitatively the crystallization behavior of PEO in the presence of PVAc very well.

On the basis of the results from both experiment and calculation, we conclude that the formed structure of PEO and PVAc blends transforms from interlamellar morphology to interfi- 
Table IV. Experimental and Calculated Data via a Combination of WAXD and SAXS for Blends of PEO and PVAc Crystallized at $50{ }^{\circ} \mathrm{C}$ for $24 \mathrm{~h}$

\begin{tabular}{ccccccccccccc}
\hline $\mathrm{wt}_{\mathrm{PEO}}$ & $\omega_{\mathrm{mc}}$ & $X_{\mathrm{CL}}$ & $X_{\mathrm{L}}$ & $f_{\mathrm{C}}$ & $\phi_{\mathrm{PEO}, \mathrm{A}}$ & $\phi_{\mathrm{PVAc}}$ & $\phi_{\mathrm{PVAc}, \text { out }}$ & $\phi_{\mathrm{PVAc}, \text { in }}$ & $\begin{array}{c}Q_{\text {cal }} \\
\left(\times 10^{19} \mathrm{~cm}^{-4}\right)\end{array}$ & $\begin{array}{c}Q_{\text {exp }} \\
(\operatorname{arbitrary} \\
\text { units })\end{array}$ & $\begin{array}{c}Q_{\text {cal }} / Q_{\text {exp }} \\
\left(\times 10^{19} \mathrm{~cm}^{-4}\right)\end{array} \begin{array}{c}\text { Scaled } Q_{\text {exp }} \\
\left(\times 10^{19} \mathrm{~cm}^{-4}\right)\end{array}$ \\
\hline 1.0 & 0.825 & 0.797 & 1.03 & 0.839 & 0.175 & 0 & 0 & 0 & 1.799 & 0.081 & 22.2 & 1.677 \\
0.9 & 0.783 & 0.786 & 0.996 & 0.883 & 0.114 & 0.103 & 0.004 & 0.099 & 1.376 & 0.070 & 19.7 & 1.449 \\
0.7 & 0.630 & 0.724 & 0.870 & 0.917 & 0.063 & 0.307 & 0.130 & 0.177 & 1.074 & 0.054 & 19.9 & 1.118 \\
0.5 & 0.420 & 0.650 & 0.646 & 0.864 & 0.073 & 0.507 & 0.354 & 0.153 & 0.971 & 0.046 & 21.1 & 0.952 \\
0.3 & 0.160 & 0.380 & 0.421 & 0.557 & 0.141 & 0.699 & 0.579 & 0.120 & 0.818 & 0.028 & 29.2 & 0.580 \\
\hline
\end{tabular}

brillar morphology with the addition of amorphous PVAc. As the amount of PVAc added to PEO increases, although $\phi_{\text {PVAc,in }}$, as listed in Table IV, increases and then decreases, $\phi_{\text {PVAc,out }}$ keeps increasing from 0 to $58 \%$. That is, more PVAc chains are excluded from the interlamellar region into the interfibrillar region with decreasing $\mathrm{wt}_{\mathrm{PEO}}$. In addition, we find that $f_{\mathrm{C}}$ is over $80 \%$ when $\mathrm{wt}_{\mathrm{PEO}} \geq 0.5$ and then drops to $56 \%$ as wt $\mathrm{t}_{\mathrm{PEO}}$ decreases to 0.3 , as listed in Table IV.

The calculated invariant $Q$ for the blends with $\mathrm{wt}_{\mathrm{PEO}}=0.3$ is substantially overestimated, which we believe happens because as $X_{\mathrm{L}}$ decreases and the exclusion of amorphous PVAc becomes larger, the spherulite morphology becomes more open. ${ }^{29}$ Therefore, blends of partial crystalline PEO in the presence of large amounts of amorphous PVAc

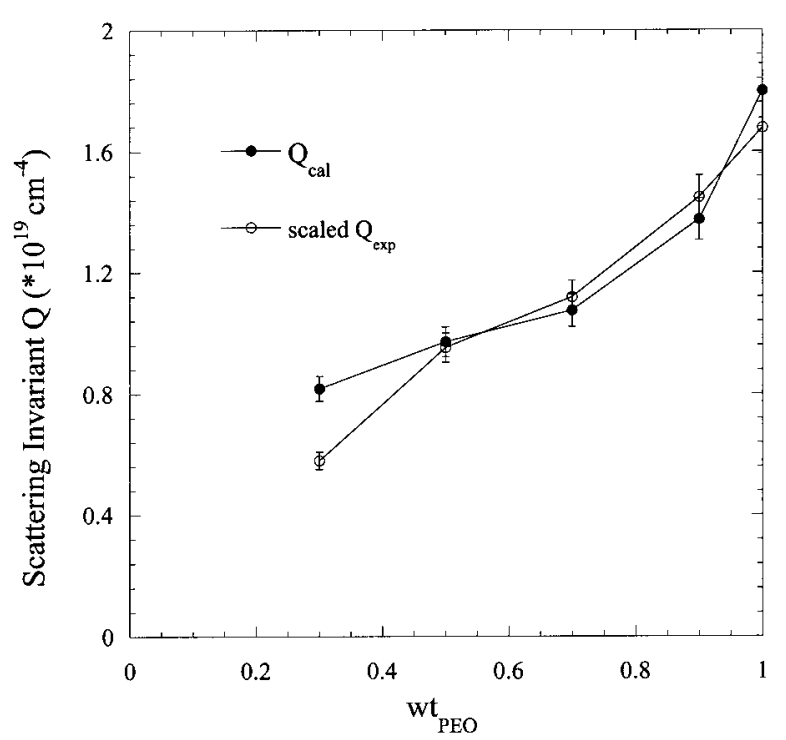

Figure 9. Comparison of $Q_{\text {cal }}$ and $Q_{\exp }$ multiplied by the average ratio $Q_{\text {cal }} / Q_{\exp }(\sim 20.7)$ for $\mathrm{PEO} / \mathrm{PVAc}$ blends with various values of $\mathrm{wt}_{\mathrm{PEO}}$ crystallized at 50 ${ }^{\circ} \mathrm{C}$ for $24 \mathrm{~h}$. cannot form densely packed lamellar stacks. As shown in Figure 5, the 1D correlation function $\gamma(x)$ becomes more diffuse. Hence, the meansquared scattering length density difference between the crystalline layer and amorphous layer $\left(\rho_{\mathrm{C}}-\rho_{\mathrm{A}}\right)^{2}$ as well as $Q$ should be smaller than the calculated values.

\section{Chain Conformation Behavior}

We employ SANS experiments to examine the chain conformation behavior for the blends with $\mathrm{wt}_{\mathrm{PEO}}=0.7,0.5$, and 0.3 from 50 to $70{ }^{\circ} \mathrm{C}$. As shown in Figure 10, where we plot $I$ versus $q$ for $\mathrm{wt}_{\mathrm{PEO}}=0.5, I$ is stronger at $50{ }^{\circ} \mathrm{C}$ because the PEO chains crystallize and the blends form a

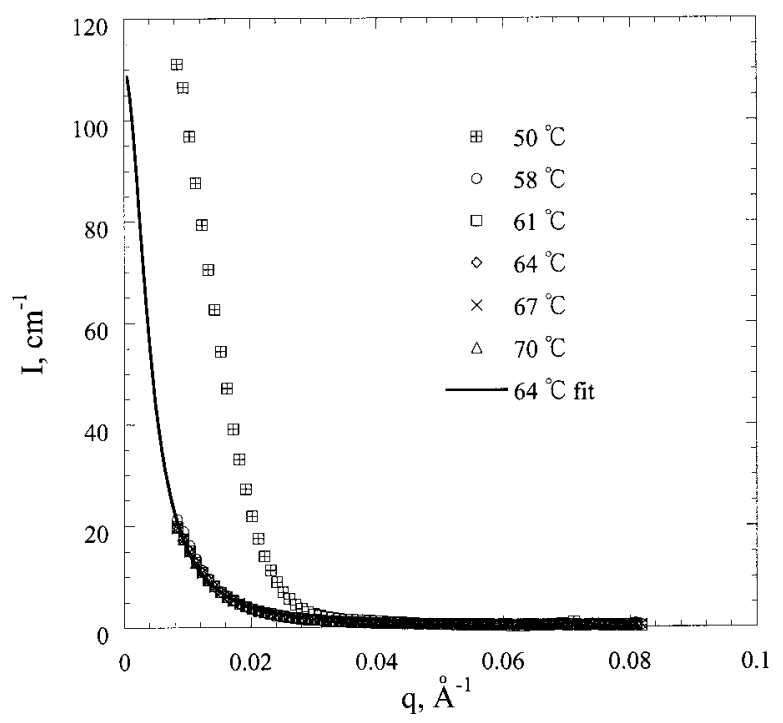

Figure 10. Scattered intensity $I(q)$ versus $q$ from SANS measurements for $\mathrm{wt}_{\mathrm{PEO}}=0.5 \mathrm{PEO} / \mathrm{PVAc}$ blends at the indicated temperatures. The solid line is the best fit of the data at $T=64{ }^{\circ} \mathrm{C}$ to the RPA expression in eq 10 . 
Table V. Experimental Values of $l_{\text {ave }}^{2} / v_{\mathrm{o}}$ and $\chi / v_{\mathrm{o}}$ for PEO/PVAc Systems from the Fitting of SANS Data to RPA in Eq 10

\begin{tabular}{ccccccc}
\hline $\mathrm{wt}_{\mathrm{PEO}}$ & $\phi_{\mathrm{PEO}}$ & $\begin{array}{c}T \\
\left({ }^{\circ} \mathrm{C}\right)\end{array}$ & $\begin{array}{c}l_{\text {ave }}^{2} / v_{\mathrm{o}} \\
\left(\AA^{2} / \mathrm{cm}^{3} / \mathrm{mol}\right)\end{array}$ & $\begin{array}{c}\chi / v_{\mathrm{o}} \\
\left(\times 10^{-5} ; \mathrm{mol} / \mathrm{cm}^{3}\right)\end{array}$ & $\begin{array}{c}R_{\mathrm{g}, \mathrm{PEO}} \\
(\AA)\end{array}$ & $\begin{array}{c}R_{\mathrm{g}, \mathrm{PVAc}} \\
(\AA)\end{array}$ \\
\hline 0.3 & 0.313 & 58 & 0.459 & 2.578 & 82.3 & 85.6 \\
0.3 & 0.313 & 61 & 0.463 & 2.571 & 82.6 & 86.0 \\
0.3 & 0.313 & 64 & 0.458 & 2.568 & 82.2 & 85.5 \\
0.3 & 0.313 & 67 & 0.464 & 2.570 & 82.7 & 86.1 \\
0.3 & 0.313 & 70 & 0.448 & 2.555 & 81.3 & 84.6 \\
0.5 & 0.515 & 58 & 0.178 & 2.153 & 51.2 & 53.3 \\
0.5 & 0.515 & 61 & 0.180 & 2.140 & 51.5 & 53.6 \\
0.5 & 0.515 & 64 & 0.179 & 2.139 & 51.4 & 53.5 \\
0.5 & 0.515 & 67 & 0.180 & 2.138 & 51.5 & 53.6 \\
0.5 & 0.515 & 70 & 0.178 & 2.519 & 51.3 & 53.3 \\
0.7 & 0.713 & 58 & 0.161 & 2.518 & 48.7 & 50.7 \\
0.7 & 0.713 & 61 & 0.163 & 2.517 & 49.0 & 51.0 \\
0.7 & 0.713 & 64 & 0.161 & 2.520 & 48.7 & 50.7 \\
0.7 & 0.713 & 67 & 0.163 & 2.515 & 49.0 & 51.0 \\
0.7 & 0.713 & 70 & 0.160 & 48.6 & 50.5 \\
\hline
\end{tabular}

crystalline/amorphous periodic structure. As the temperature increases to $58{ }^{\circ} \mathrm{C}$ and even higher, the scattered intensity drops because the PEO chains melt and thus the ordered microstructures are destroyed. In fact, the melt-miscible PEO and PVAc chains are homogeneously mixed. Only the contrast between the randomly distributed PEO and PVAc chains contributes to the scattered intensity.

It is well known that the total scattering for a binary $\mathrm{A}$ and $\mathrm{B}$ mixture in the one-phase region is well described by random phase approximation (RPA): ${ }^{30,31}$

$$
\begin{aligned}
I(q) & =N_{\mathrm{o}}\left(\frac{b_{\mathrm{A}}}{v_{\mathrm{A}}}-\frac{b_{\mathrm{B}}}{v_{\mathrm{B}}}\right)^{2} \\
& \times\left(\frac{1}{\phi_{\mathrm{A}} Z_{\mathrm{A}} v_{\mathrm{A}} P_{\mathrm{A}}(q)}+\frac{1}{\phi_{\mathrm{B}} Z_{\mathrm{B}} v_{\mathrm{B}} P_{\mathrm{B}}(q)}-2 \frac{\chi}{v_{\mathrm{o}}}\right)^{-1}
\end{aligned}
$$

where $b_{I}$ is the scattering length per monomer $I$; $v_{I}$ and $v_{\mathrm{o}}$ are the monomer volumes of the $I$ th segment and the reference unit, respectively; $Z_{I}$ is the degree of polymerization of component $I ; \phi_{I}$ is the volume fraction of component $I$ and is calculated with densities of 1.12 and $1.19 \mathrm{~g} / \mathrm{cm}^{3}$ for $100 \%$ amorphous PEO and PVAc, respectively; and $\chi$ is the interaction parameter between components A and B. The single-chain form factor of component $I, P_{I}(q)$, is given by the Debye function:

$$
P_{I}(q)=\frac{2}{x^{2}}[\exp (-x)-1+x], I=\mathrm{A} \text { or } \mathrm{B}
$$

where $x=q^{2} R_{g, I}^{2}$, in which $R_{\mathrm{g}, I}$ is the radius of gyration of component $I$.

The scattering data are fitted to eq 10 so that the values of the interaction parameter $\chi / v_{0}$ and the radii of gyration of PEO and PVAc, $R_{\mathrm{g}, \mathrm{PEO}}$ and $R_{\mathrm{g}, \mathrm{PVAc}}$, are obtained. Because $R_{\mathrm{g}, \mathrm{PEO}}$ and $R_{\mathrm{g}, \mathrm{PVAc}}$ are strongly coupled in eq 10 , they cannot be varied independently. A single averaged parameter $l_{\text {ave }}^{2} / v_{\mathrm{o}}$ is introduced in the fitting procedure with $^{31}$

$$
R_{\mathrm{g} I}^{2}=\frac{Z_{I} v_{I}}{6}\left(\frac{l_{\mathrm{ave}}^{2}}{v_{\mathrm{o}}}\right), I=\mathrm{A} \text { or B }
$$

Thus, only two independent parameters, $l_{\text {ave }}^{2} / v_{\mathrm{o}}$ and $\chi / v_{0}$, exist in the fitting procedure. As shown in Figure 10, the scattered intensities for the blends with $\mathrm{wt}_{\mathrm{PEO}}=0.5$ at $T \geq 58{ }^{\circ} \mathrm{C}$ are well fitted by eq 10 for the whole $q$ range. Similar results are obtained for $\mathrm{wt}_{\mathrm{PEO}}=0.3$ and 0.7 . Furthermore, the values of $l_{a v e}^{2} / v_{\mathrm{o}}$ and $\chi / v_{\mathrm{o}}$ obtained from the fits as a function of $\mathrm{wt}_{\mathrm{PEO}}$ and temperature are given in Table V. It is clear that the interaction parameter $\chi / v_{0}$ is very small (close to zero) and independent of the volume fraction and temperature range studied here. In terms of $l_{\text {ave }}^{2} / v_{\mathrm{o}}, R_{\mathrm{g}, \mathrm{PEO}}$ and $R_{\mathrm{g}, \mathrm{PVAc}}$ calculated from eq 12 are around 50-85 $\AA$ for $\mathrm{wt}_{\mathrm{PEO}}=0.7-0.3$. From a comparison with $L_{\mathrm{A}}$ results obtained for systems crystallized at $50{ }^{\circ} \mathrm{C}$ (as shown in Table III), it is clear that the amorphous layer thickness is always larger than $R_{\mathrm{g}, \mathrm{PVAc}}$. As such, there is enough 
space for the amorphous PVAc chains with a random-coil configuration.

\section{SUMMARY}

We have employed WAXD, SAXS, and SANS experiments to study the crystallization and chain conformation behavior of melt-miscible semicrystalline PEO and amorphous PVAc mixtures. From the WAXD analysis for the blends with $w t_{\text {PEO }} \geq 0.3$ quenched from the melt state to a temperature below the melting point of PEO, such as $50{ }^{\circ} \mathrm{C}$, the crystalline $\mathrm{PEO}$ belongs to the monoclinic system, and the unit-cell parameters $(a, b, c$, and $\beta)$ are independent of $\mathrm{wt}_{\mathrm{PEO}}$. However, $\omega_{\mathrm{mc}}$ determined from WAXD decreases with an increasing amount of PVAc. SAXS results show that the mixtures quenched to $50{ }^{\circ} \mathrm{C}$ form an ordered crystalline/amorphous lamellar structure. In a combination of the results of $\omega_{\mathrm{mc}}$ from WAXD and $X_{\mathrm{CL}}$ from SAXS, $X_{\mathrm{L}}\left(\omega_{\mathrm{mc}} / X_{\mathrm{CL}}\right)$ is obtained. As $\mathrm{wt}_{\mathrm{PEO}}$ decreases from 1.0 to $0.3, X_{\mathrm{L}}$ decreases from 100 to $42 \%$. Furthermore, we find that the scattering invariant deduced from the 1D correlation function follows the following expression: $Q=X_{\mathrm{L}} X_{\mathrm{CL}}\left(1-X_{\mathrm{CL}}\right)\left(\rho_{\mathrm{C}}-\rho_{\mathrm{A}}\right)^{2}$. Our results from both experiment and calculation make clear that the structure of PEO and PVAc blends transforms from interlamellar morphology to interfibrillar morphology with the addition of amorphous PVAc. When $\mathrm{wt}_{\mathrm{PEO}}$ is close to 1 , the samples are fully spaced-filled with lamellar stacks. That is, the amorphous PVAc chains are located between the crystalline interlamellae. As the amount of PVAc added to PEO increases, more PVAc chains are excluded from the interlamellar region into the interfibrillar region. With the addition of amorphous PVAc, $L_{\mathrm{A}}$, as well as the average long spacing, increases, whereas $L_{\mathrm{C}}$ decreases.

Although the PEO chains in the blend systems crystallize at $50{ }^{\circ} \mathrm{C}$, once the systems are heated to around $58{ }^{\circ} \mathrm{C}$, the formed lamellar structures disappear very quickly by melting. The scattering data from SANS experiments are well described by RPA, indicating that both the PEO and PVAc chains are randomly distributed over all length scales. In particular, the interaction parameter is very small (close to zero) and independent of $\mathrm{wt}_{\mathrm{PEO}}$ and temperature, as expected. Because $R_{\mathrm{g}, \mathrm{PVAc}}$ with a random-coil configuration determined from SANS is smaller than $L_{\mathrm{A}}$ from SAXS for the blends with $\mathrm{wt}_{\mathrm{PEO}} \geq 0.3$, we believe that the amorphous PVAc chains still persist with a random-coil configuration even when the blends form an ordered structure.

The authors thank Dr. T. L. Lin and Dr. W. C. Liu for their assistance with the SAXS measurements and Dr. Charles C. Han for his assistance with the SANS 8m measurements. This work was supported by the National Science Council of the Republic of China (grant NSC 89-2216-E-011-019) and the Institute of Nuclear Energy Research of the Republic of China (grant 892001INER027).

\section{REFERENCES AND NOTES}

1. Martuscelli, E.; Silvestre, C.; Gismondi, C. Makromol Chem 1985, 186, 2161.

2. (a) Inaba, N.; Sato, K.; Suzuki, S.; Hashimoto, T. Macromolecules 1986, 19, 1690; (b) Inaba, N.; Sato, K.; Suzuki, S.; Hashimoto, T. Macromolecules 1988, 21, 407.

3. Ito, H.; Russell, T. P.; Wignall, G. D. Macromolecules 1987, 20, 2213.

4. Martuscelli, E.; Vicini, L.; Seves, A. Makromol Chem 1987, 188, 607.

5. Silvestre, C.; Karasz, F. E.; Macknight, W.; Martuscelli, E. Eur Polym J 1987, 23, 745.

6. Kalfoglou, N. K.; Sotiropoulou, D. D.; Margaritis, A. G. Eur Polym J 1988, 24, 389.

7. Burghardt, W. R. Macromolecules 1989, 22, 2482.

8. Addonozio, M. L.; Martuscelli, E.; Silvestre, C. J Polym Mater 1990, 7, 63.

9. Han, C. D.; Chung, H. S.; Kim, J. K. Polymer 1992, 33, 546.

10. Yin, J.; Alfonso, G. C.; Turturro, A.; Pedemonte, E. Polymer 1993, 34, 1465.

11. Talibuddin, S.; Wu, L.; Runt, J.; Lin, J. S. Macromolecules 1996, 29, 7527.

12. Chen, X.; Yin, J.; Alfonso, G. C.; Pedemonte, E.; Turturro, A.; Gattiglia, E. Polymer 1998, 39, 4929.

13. Chen, H. L.; Hsiao, M. S. Macromolecules 1998, 31, 6579.

14. Seki, M.; Nakano, H.; Yamauchi, S.; Suzuki, J.; Matsushita, Y. Macromolecules 1999, 32, 3227.

15. Lim, S. W.; Lee, K. H.; Lee, C. H. Polymer 1999, 40, 2837.

16. Huang, C. I. J Polym Res, in press.

17. Strobl, G. R.; Schneider, M. J Polym Sci Polym Phys Ed 1980, 18, 1343.

18. Santa Cruz, C. S.; Stribeck, N.; Zachmann, H. G.; Balta Calleja, F. J. Macromolecules 1991, 24, 5980.

19. Stribeck, N.; Alamo, R. G.; Mandelkern, L.; Zachmann, H. G. Macromolecules 1995, 28, 5029.

20. Albrecht, T.; Strobl, G. Macromolecules 1996, 29, 783. 
21. Wang, Z. G.; Hsiao, B. S.; Fu, B. X.; Liu, L.; Yeh, F.; Sauer, B. B.; Chang, H.; Schultz, J. M. Polymer 2000, 41, 1791.

22. Marcos, J. I.; Orlandi, E.; Zerbi, G. Polymer 1990, $31,1899$.

23. Takahashi, Y.; Tadokoro, H. Macromolecules 1973, 6,672 .

24. Ruland, W. J. J Appl Crystallogr 1971, 4, 70.

25. Debye, P.; Bueche, A. M. J Appl Phys 1949, 20, 518.

26. Debye, P.; Anderson, H. R., Jr.; Brumberger, H. J Appl Phys 1957, 28, 679.
27. (a) Gehrke, R.; Riekel, C.; Zachmann, H. G. Polymer 1989, 30, 1582; (b) Kruger, K. N.; Zachmann, H. G. Macromolecules 1993, 26, 5202.

28. Brandrup, J.; Immerfrut, E. H. Polymer Handbook; Wiley: New York, 1989.

29. Saito, H.; Stuhn, B. Macromolecules 1994, 27, 216.

30. de Gennes, P. G. Scaling Concepts in Polymer Physics; Cornell University Press: Ithaca, NY, 1979.

31. Shibayama, M.; Yang, H.; Stein, R. S.; Han, C. C. Macromolecules 1985, 18, 2179. 